\title{
Effect of Fopius arisanus oviposition experience on parasitization of Bactrocera dorsalis
}

\author{
Rafael da Silva Gonçalves • Nicholas Chirivas Manoukis • Dori Edson Nava
}

Received: 8 April 2016/Accepted: 26 June 2017/Published online: 10 July 2017

(C) The Author(s) 2017. This article is an open access publication

\begin{abstract}
Fopius arisanus (Sonan) (Hymenoptera: Braconidae) is an important fruit fly parasitoid, successfully introduced in programs of classical biological control around the world. One aspect of its reproductive biology that has received increasing attention is the role of learning on parasitization by individual females. In this study, we examined the effect of previous oviposition opportunities on the reproductive success and progeny sex ratio of $F$. arisanus on eggs of Bactrocera dorsalis Hendel (Diptera: Tephritidae). Our results indicate that the proportion of eggs parasitized and parasitoid yield both increase with increasing experience, as acquired
\end{abstract}

Handling Editor: Stefano Colazza.

R. S. Gonçalves $(\bowtie)$

Departamento de Fitossanidade, Programa de Pós-

Graduação em Fitossanidade, Faculdade de Agronomia

Eliseu Maciel, Universidade Federal de Pelotas,

Capão do Leão, RS 96010-900, Brazil

e-mail: rafaeldasilvagoncalves@gmail.com

\section{N. C. Manoukis}

United States Department of Agriculture - Agricultural Research Service, US Pacific Basin Agricultural Research Center, 64 Nowelo St., Hilo, HI 96720, USA

e-mail: nicholas.manoukis@ ars.usda.gov

\section{E. Nava}

Empresa Brasileira de Pesquisa Agropecuária - Embrapa

Clima Temperado, Rodovia BR 392 km 78,

Caixa Postal 403, Pelotas, RS 96010-971, Brazil

e-mail: dori.edson-nava@embrapa.br by individual females via previous oviposition opportunities. These effects are shown to be unrelated to parasitoid age out to three weeks, which we found not to have an effect on parasitization, yield, or sex ratio. We discuss the implications of our results on mass rearing and also in terms of the efficiency of this biological control agent in the field.

Keywords Braconidae $\cdot$ Tephritidae $\cdot$ Biological control · Mass rearing

\section{Introduction}

The opiine solitary koinobiont egg-larval parasitoid Fopius arisanus (Sonan) is an important biological control agent against tephritid fruit flies, particularly Bactrocera dorsalis (Hendel) and Ceratitis capitata (Wiedemann), though it is also known to attack Bactrocera latifrons (Hendel) and Bactrocera cucurbitae (Coquillett) (Bokonon-Ganta et al. 2007; Harris et al. 2010). F. arisanus is thought to be a highly efficient parasitoid (Clausen et al. 1965; Rousse et al. 2005; Vargas et al. 2012b), with parasitism levels exceeding 50\% in the field in some instances (Vargas et al. 1993; Purcell 1998; Vargas et al. 2012a). Due to successful introductions and establishments, initially in Hawaii and more recently in French Polynesia, this braconid wasp has been introduced to ten Pacific island-nations, La Reunion Island, Australia, Israel, 
Mexico, Senegal and Costa Rica (Vargas et al. 2007; Mohamed et al. 2010; Vargas et al. 2012a). Indeed, $F$. arisanus has been found to displace other parasitoid species in Hawaii, where it was one of 32 natural enemies introduced from 1947 to 1953 (Bess et al. 1961; Vargas et al. 2012a).

Extending the use of $F$. arisanus as a biological control agent has been helped by the development of mass rearing techniques on artificial diet for this species (Bautista et al. 1999; Manoukis et al. 2011), as it was historically found to be difficult to rear this species in colony (Chong 1962; Snowball et al. 1962; Ramadan et al. 1992, 1994). Mass rearing allows augmentative release programs, increasing the probability of parasitoid establishment. Critical reproductive and behavioral parameters had to be measured for colony maintenance and mass rearing to be feasible and then improved, including the adaptability of differing strains to laboratory conditions (Harris and Okamoto 1991), the age of peak oviposition (Ramadan et al. 1994; Wang and Messing 2003) and effect of female age on offspring sex ratio (Bautista et al. 1998).

Beyond these fundamental studies, aimed at enabling mass rearing, an aspect of the reproductive biology in fruit fly hymenopterous wasps that has recently received increased attention is the role of learning (Giunti et al. 2015). Visual cues have been shown to be essential to learned host-seeking behavior in Psyttalia concolor (Szépligeti) (Hymenoptera: Braconidae) (Benelli and Canale 2012) and Diachasmimorpha longicaudata (Ashmead) (Hymenoptera: Braconidae) (Segura et al. 2007). For F. arisanus, there has been some research on learning via association of visual and olfactory cues indicating that these might play a role in host finding (Dukas and Duan 2000; Rousse et al. 2007). In addition to finding fruit with suitable host eggs or larvae, learning has been argued to be adaptive in this species to help individual females to avoid superparasitization (Wang and Messing 2008).

In this study we examine the role of oviposition experience on parasitization rates, parasitoid yield and sex ratio, reflecting overall parasitization efficiency by $F$. arisanus. Our results indicate that there is a significant increase in the parasitization efficiency of female $F$. arisanus with oviposition experience, and that this is independent of female age, at least out to three weeks. In addition, our results have implications for the optimization of mass rearing operations of $F$. arisanus as well as for the effectiveness of this parasitoid in the field.

\section{Materials and methods}

Insects

All insects used in this research were from the research colonies maintained at the USDA-ARS Daniel K. Inouye US Pacific Basin Agricultural Research Center (DKI-PBARC) in Hilo, Hawaii Island, USA. Bactrocera dorsalis have been maintained according to Vargas (1989) and Spencer and Fujita (1997), originally started from fruit collections conducted in Puna, Hawaii Island, in 1984 and periodically refreshed with wild insects from the same area. B. dorsalis are maintained on a modified version of the artificial diet described by Tanaka et al. (1969).

Fopius arisanus used in this study have been maintained using standard methodology (Bautista et al. 1999; Manoukis et al. 2011). This colony was initiated around 1995, and is maintained in small cages $(0.25 \times 0.25 \times 0.25 \mathrm{~m})$ at a density of about 1000 adults per cage. All rearing and experimentation was conducted at DKI-PBARC under standard conditions (temperature $=27 \pm 1{ }^{\circ} \mathrm{C}$; $\mathrm{RH}=80 \pm 10 \%$; photoperiod $=12: 12 \mathrm{~L}: \mathrm{D})$.

Experiment 1: Effect of experience on oviposition by female $F$. arisanus

This experiment included two parts: preparation (exposure to eggs) and the assay. During the preparation phase, four groups of $100 \mathrm{~F}$. arisanus females, putatively mated and aged three days, were maintained in standard $25 \mathrm{~cm}$ cubical cages following Manoukis et al. (2011). Each of the four groups was subjected to one of four treatments: T1-no previous oviposition experience (naïve); T2-one previous oviposition opportunity (at age three days); T3 - three previous oviposition opportunities (at ages three, five and seven days); T4-five previous oviposition opportunities (daily between ages three and seven days). All preparation treatments occurred between the third and seventh day of life for the females. Oviposition opportunities consisted of making available an agar plate with $4000 \mathrm{~B}$. dorsalis eggs to each group of 100 females for $22 \mathrm{~h}$, between $10 \mathrm{~h} 00$ and 
8h00. All eggs from these oviposition opportunities were discarded.

When all $F$. arisanus in a replicate were ten days old, the week following the preparation phase, we conducted parasitization efficiency assays. For this, 50 randomly selected females from each treatment were placed in groups of ten in small plastic screened containers (400 ml volume). 2002 -h old $B$. dorsalis eggs on a $4 \mathrm{~cm}$ diameter piece of damp paper, placed on a small agar plate $(6 \mathrm{~cm}$ diameter $\times 0.5 \mathrm{~cm}$ height), were introduced to the small cages for $22 \mathrm{~h}$ from $10 \mathrm{~h} 00$ to $8 \mathrm{~h} 00$ (20 eggs per female $F$. arisanus). As a control, two groups of 100 eggs, unexposed to the parasitoid, were held under the same conditions to check fruit fly emergence rates.

After exposure during the assay, 50 eggs from each container were dissected to measure percent parasitized (fruit fly eggs with one parasitoid egg) and superparasitized eggs (fruit fly eggs containing more than one parasitoid egg). The remaining 150 eggs per container were transferred to larval diet and checked $24 \mathrm{~h}$ later for eclosion, then held under standard conditions (Manoukis et al. 2011). Puparia produced from the batches of 150 eggs were held by batch in $250 \mathrm{ml}$ screened plastic containers and checked regularly for four weeks to determine the number of male and female $F$. arisanus and B. dorsalis emerged from puparia and the number of unemerged specimens. For fruit flies we considered unemerged those individuals that completed metamorphosis but did not come out of puparia. For parasitoids, were considered as unemerged those with complete metamorphosis but still in puparia and parasitoids in immature stages (larvae and pupae). This experiment was repeated four times between April and May 2015.

\section{Experiment 2: Effect of $F$. arisanus age on reproduction}

In experiment 2 we used female $F$. arisanus of three different ages: one, two or three weeks old. All females were held with males (about 100 each in $25 \mathrm{~cm}$ cubical cages), and so had opportunities to mate, but they were not presented with fruit fly eggs, so none had oviposition experience. As in experiment 1 , we randomly selected ten females and placed them in $400 \mathrm{ml}$ plastic screened containers, five containers per age per treatment. Once in the small containers, females were offered 200 B. dorsalis eggs for $22 \mathrm{~h}$ as in experiment 1 . This experiment was repeated four times in June 2015.

Statistical analysis

For experiment 1 , the response variables were percent parasitism and superparasitism, hatching rate, proportion emergence and sex ratio (percent females). These were checked for normality via Shapiro-Wilk test, and for heteroscedasticity via Hartley's test. Residual dispersion was checked visually. Following these tests, the response variable superparasitism was transformed via arcsine of the square root. For comparisons between treatments we used an analysis of variance (ANOVA). When significant differences were found, averages were compared via Tukey's range test. For the comparisons of sex ratios we used the non-parametric Friedman's test, because the assumptions of the ANOVA were not met. Throughout, we used $\alpha \leq 0.05$ to determine statistical significance.

For the results from experiment 2, again we checked response variables for normality, heteroscedasticity and residual independence. Following these tests, the response variable sex ratio was transformed via Box-Cox transformation. For comparisons between treatments we used an ANOVA. All post-hoc comparisons were again conducted via Tukey's test. All analyses were conducted in $\mathrm{R}$ version 3.1.3 (R Development Core Team 2015).

\section{Results}

\section{Experiment 1}

There was a significant difference in the proportion of parasitized $\left(F_{3,9}=8.10 ; p=0.0063\right)$ and superparasitized $\left(F_{3,9}=8.73 ; p=0.0049\right) B$. dorsalis eggs by $F$. arisanus of differing experience $(0-5$ previous exposures to eggs). Female $F$. arisanus with 3-5 previous oviposition opportunities had the highest rates of both parasitism and superparasitism (Fig. 1) compared with those with one or no previous opportunities. We found no significant difference in the hatching rates between the treatments and control (Fig. $1 ; F_{4,12}=0.90 ; p=0.4915$ ).

Previous oviposition opportunities significantly affected the proportion of parasitoids that emerged 


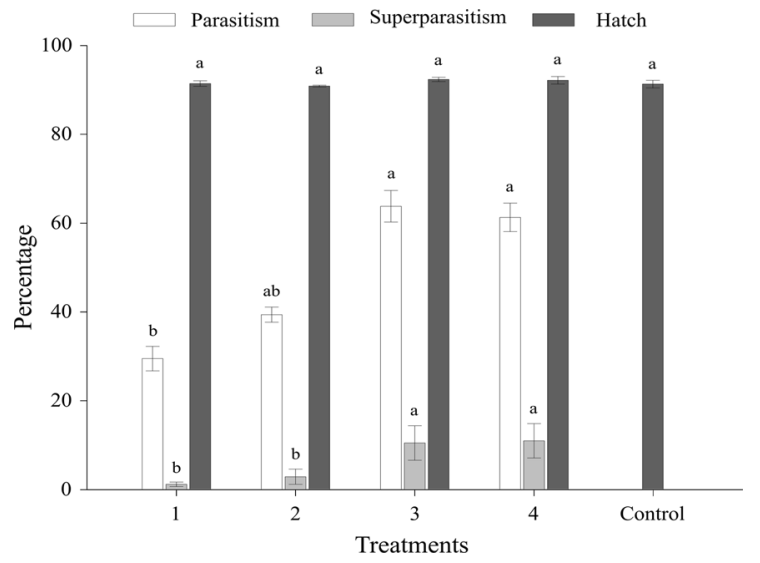

Fig. 1 Parasitism, superparasitism and hatch (average \pm SE) of $B$. dorsalis eggs exposed to females of $F$. arisanus of the same age, but with different oviposition experience levels. Treatments: 1 naïve, 2 one oviposition experience on the third day of life, 3 three oviposition experiences, third, fifth and seventh day of life, 4 five oviposition experiences (daily from the third to the seventh day of life). Bars with the same color followed by a same letter are not statistically different. ANOVA followed by Tukey's HSD test $(\alpha=0.05)$

from the assay $\left(F_{3,9}=7.65 ; p=0.0075\right)$. Specifically, we found that females with three oviposition opportunities produced the most parasitoids in the assay, around $80 \%$, which was significantly higher than females that had no previous oviposition experience (Fig. 2). However, we did not observe a significant difference in the percentage of unemerged parasitoids between the treatments $\left(F_{3,9}=2.63\right.$; $p=0.1140$ ). We also observed no significant difference in sex ratio between treatments with varying previous oviposition experience (Fig. $2 ; \chi^{2}=0.07$; $d f=3 ; p=0.9944)$.

\section{Experiment 2}

Table 1 shows that the percent parasitism by naïve $F$. arisanus varied between 22.2 and $36.0 \%$, but this variation was not statistically significant $\left(F_{2,6}=1.56\right.$; $p=0.2830)$. We observed no effect of parasitoid age on superparasitism $\left(F_{2,6}=4.49 ; p=0.0642\right)$ or proportion of eggs hatched $\left(F_{3,9}=0.51 ; p=0.6801\right)$. We found no significant effect of female parasitoid age on proportion of parasitoids produced (Table 2; $\left.F_{2,6}=2.71 ; \quad p=0.1447\right)$, unemerged parasitoids observed $\left(F_{2,6}=2.44 ; p=0.1672\right)$, or sex ratio of the resulting parasitoids $\left(F_{2,6}=0.12 ; p=0.8855\right)$.

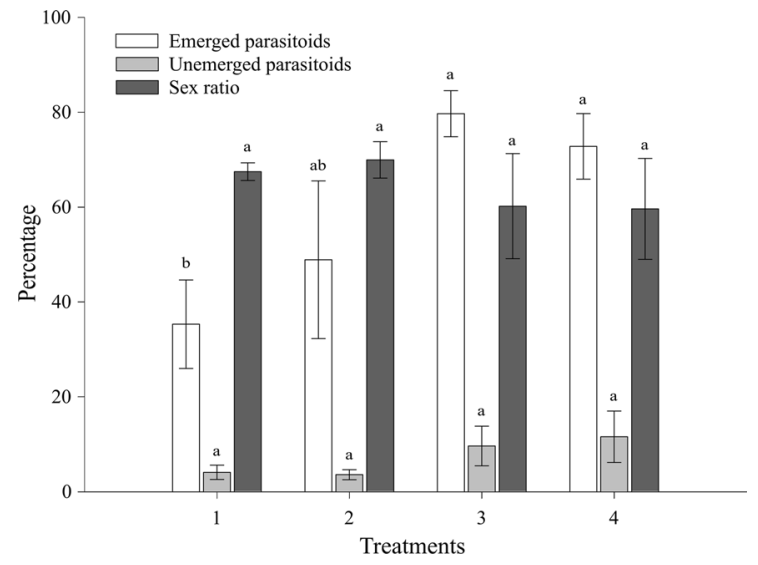

Fig. 2 Percentage of emerged and unemerged parasitoids, and sex ratio (average \pm SE) of offspring population produced by females of $F$. arisanus of the same age, but with different oviposition experience levels. Treatments: 1 naïve, 2 one oviposition experience on the third day of life, 3 three oviposition experiences, third, fifth and seventh day of life, 4 five oviposition experiences (daily from the third to the seventh day of life). Bars with the same color followed by a same letter are not statistically different. Emerged and unemerged parasitoids-ANOVA followed by Tukey's HSD test $(\alpha=0.05)$. Sex ratio-Friedman test $(\alpha=0.05)$

\section{Discussion}

Our data show a clear effect of previous oviposition experience on parasitization efficiency. Female $F$. arisanus with 3-5 previous oviposition opportunities during the first week post-eclosion parasitized host eggs at about double the rate of females of the same age but without previous experience (Fig. 1). Consequently, more offspring were produced by females with previous oviposition experience. A mechanism that might account for our observation was suggested by Wang and Messing (2003), who found that exposure to host eggs and the act of oviposition stimulates egg development in the female parasitoid, and retards resorbtion of eggs already produced.

Under mass rearing conditions, $F$. arisanus are generally allowed to oviposit starting one week after eclosion, through the third week (Manoukis et al. 2011). Our results in the present study suggest that an oviposition opportunity during the first week could increase the parasitization rate after the first week, increasing the yield of parasitoids under mass rearing. The yield could be increased both by the additional oviposition and by increased emergence in production during weeks 2 and 3. Our results are in agreement 
Table 1 Percentage of parasitism, superparasitism and hatch ( $\pm \mathrm{SE}$ ) of $B$. dorsalis eggs exposed to females of $F$. arisanus of different ages

\begin{tabular}{lllr}
\hline Age (week) & Parasitism $(\%)$ & Superparasitism $(\%)$ & Hatch $(\%)$ \\
\hline 1 & $22.20 \pm 8.68 \mathrm{a}$ & $0.90 \pm 0.34 \mathrm{a}$ & $91.97 \pm 0.36 \mathrm{a}$ \\
2 & $36.00 \pm 4.31 \mathrm{a}$ & $4.70 \pm 1.54 \mathrm{a}$ & $91.23 \pm 1.35 \mathrm{a}$ \\
3 & $32.70 \pm 7.48 \mathrm{a}$ & $2.30 \pm 0.68 \mathrm{a}$ & $90.07 \pm 1.27 \mathrm{a}$ \\
Control & NA & NA & $91.25 \pm 1.24 \mathrm{a}$ \\
\hline
\end{tabular}

Values followed by a same letter in the column are not statistically different. ANOVA followed by Tukey's HSD test ( $\alpha=0.05)$ NA not applicable

Table 2 Percentage of emerged and unemerged parasitoids, and sex ratio of offspring produced by females of $F$. arisanus of different ages

\begin{tabular}{lllr}
\hline Age (week) & \multicolumn{2}{l}{ Parasitoids } & \multirow{2}{*}{ Sex ratio } \\
\cline { 2 - 3 } & Emerged $(\%) \pm$ SE & Unemerged $(\%) \pm$ SE & $0.70 \pm 0.01 \mathrm{a}$ \\
\hline 1 & $22.30 \pm 7.81 \mathrm{a}$ & $0.70 \pm 1.64 \mathrm{a}$ & $0.68 \pm 0.03 \mathrm{a}$ \\
3 & $44.63 \pm 8.62 \mathrm{a}$ & $3.67 \pm 1.94 \mathrm{a}$ & $0.69 \pm 0.01 \mathrm{a}$ \\
\hline
\end{tabular}

Values followed by a same letter in the column are not statistically different. ANOVA and Tukey test $(\alpha=0.05)$

with those obtained by Dukas and Duan (2000), who verified that the learning process was beneficial to the fitness of $F$. arisanus. It is important to point out that the results were similar even though there were methodological differences between the studies, for example, the use of groups of insects and the longer evaluation period (three weeks) in our study.

Rates of superparasitism increased with increasing parasitism and experience. Superparasitism is more common under mass rearing conditions compared with in the wild, where such events are maladaptive (van Alphen and Visser 1990; González et al. 2007; Montoya et al. 2012). Previous research by Wang and Messing (2008) suggested a decrease in superparasitism with increasing egg-laying experience in $F$. arisanus. The same trend was observed in $P$. concolor by Benelli et al. (2013). Those studies tracked single females, however, while we used small groups of parasitoid females. Two possible reasons for our results are (1) an elevated mature egg load in the females who have had multiple recent oviposition opportunities, stimulating high production, and (2) intra-specific competition for host eggs (Fletcher et al. 1994; Yamada and Miyamoto 1998).
Montoya et al. (2000), studying mass reared $D$. longicaudata, found an inverse relationship between superparasitism and parasitoid emergence. We did not find a significant relationship between these variables in $F$. arisanus, but note a trend of increasing unemerged parasitoids in treatments with higher rates of superparasitism, namely from females with three or five previous oviposition experiences (Figs. 1, 2).

The optimal host egg:parasitoid ratio for $F$. arisanus is considered to be 20:1 (Bautista et al. 1998). Our results suggest that the optimal ratio might vary depending on the experience of the parasitoids in question. Experience might be usefully considered in mass rearing by increasing the number of host eggs per female parasitoid for cohorts that have oviposited before. This might reduce superparasitism and increase yield.

Insects can adjust their foraging and oviposition behavior in response to egg load. Females with high mature egg loads might spend more time host seeking and less time per oviposition event (Minkenberg et al. 1992). If this general case also applies to $F$. arisanus, and considering that additional oviposition opportunities could increase the egg load, females with 
additional oviposition opportunities before release might be better at getting established in the field through increased efficiency. Translation of our findings to field efficiency of released parasitoids is complicated by several factors that can more significantly impact establishment, especially around hostfindings. The density of fruit and host eggs, for example, together with the flight ability of female parasitoids might all be more important than previous oviposition experience (Dukas and Duan 2000). An example of other factors strongly affecting parasitoid population outcomes is given by Canale and Benelli (2012) who, studying P. concolor found that females with experience with differing hosts (C. capitata and Bactrocera oleae (Rossi)) developed preferences based on the host plus substrate complex, but not the host larva alone.

Our results indicate that rates of parasitism and superparasitism were not affected by the chronological age of the female $F$. arisanus, at least not out to three weeks of age (Table 1). In addition, the proportion of emerged parasitoids were similar across ages (Table 2). This result seems to run counter to a previous study suggesting peak reproductive output at around six days post-eclosion (Ramadan et al. 1992). However, this and related studies often test the same parasitoids daily to measure realized daily fecundity, which means that the females are being exposed to eggs continuously, equivalent to experience.

We did not find an effect of female age on egg hatching rate (Table 1) or parasitoid offspring sex ratio (Table 2). This is at odds with previous results indicating a decrease in the proportion of female parasitoid offspring with increasing age (Bautista et al. 1998). As in the case of reproductive output mentioned above, those authors also exposed cohorts of $F$. arisanus to host eggs daily, confounding the effects of chronological age and previous oviposition opportunities (experience). In addition, Bautista et al. (1998) tested the effect of age over a larger range of five weeks, compared with three weeks in the current study. Our results show that offering more ovipositional opportunities (experiences) to $F$. arisanus increases their ovipositional efficiency, meaning that more parasitoids result. However, application of these results in mass rearing should be undertaken carefully, as we also observed increases in superparasitism with increasing parasitoid experience, possibly due to the limiting number of hosts available.
Acknowledgements We thank Thomas Mangine for his assistance, experience and dedication, and Caley Saragosa for assistance in conducting experiments. RSG received support from the Conselho Nacional de Ciência e Tecnologia (CNPq) and Coordenação de Aperfeiçoamento de Pessoal de Nível Superior (CAPES-Grant No. 0122/14-9) to conduct this work in Brazil and Hawaii. This work was supported by the US Department of Agriculture-Agricultural Research Service. Opinions, findings, conclusions or recommendations expressed in this publication are those of the authors and do not necessarily reflect the views of the USDA.

Open Access This article is distributed under the terms of the Creative Commons Attribution 4.0 International License (http:// creativecommons.org/licenses/by/4.0/), which permits unrestricted use, distribution, and reproduction in any medium, provided you give appropriate credit to the original author(s) and the source, provide a link to the Creative Commons license, and indicate if changes were made.

\section{References}

Bautista RC, Harris EJ, Lawrence PO (1998) Biology and rearing of the fruit fly parasitoid Biosteres arisanus: clues to insectary propagation. Entomol Exp Appl 89:79-86. doi:10.1046/j.1570-7458.1998.00384.x

Bautista RC, Mochizuki N, Spencer JP, Harris EJ, Ichimura DM (1999) Mass-rearing of the tephritid fruit fly parasitoid Fopius arisanus (Hymenoptera: Braconidae). Biol Control 15:137-144

Benelli G, Canale A (2012) Learning of visual cues in the fruit fly parasitoid Psyttalia concolor (Szépligeti) (Hymenoptera: Braconidae). BioControl 57:767-777. doi:10. 1007/s10526-012-9456-0

Benelli G, Gennari G, Canale A (2013) Host discrimination ability in the tephritid parasitoid Psyttalia concolor (Hymenoptera: Braconidae). J Pest Sci 86:245-251. doi:10. 1007/s10340-012-0471-9

Bess HA, van Den Bosch R, Haramoto FH (1961) Fruit fly parasites and their activities in Hawaii. Proc Hawaii Entomol Soc 17:367-378

Bokonon-Ganta AH, McQuate GT, Messing RH (2007) Natural establishment of a parasitoid complex on Bactrocera latifrons (Diptera: Tephritidae) in Hawaii. Biol Control 42:365-373. doi:10.1016/j.biocontrol.2007.05.019

Canale A, Benelli G (2012) Impact of mass-rearing on the host seeking behaviour and parasitism by the fruit fly parasitoid Psyttalia concolor. J Pest Sci 85:65-74. doi:10.1007/ s10340-011-0382-1

Chong M (1962) Production methods for fruit fly parasites. Proc Hawaii Entomol Soc 18:61-63

Clausen CP, Clancy DW, Chock QC (1965) Biological control of the oriental fruit fly (Dacus dorsalis Hendel) and other fruit flies in Hawaii. Agricultural Research Service, U.S. Dept. of Agriculture, Washington, D.C.

Development Core Team R (2015) R: a language and environment for statistical computing. R Foundation for Statistical Computing, Vienna 
Dukas R, Duan JJ (2000) Potential fitness consequences of associative learning in a parasitoid wasp. Behav Ecol 11:536-543. doi:10.1093/beheco/11.5.536

Fletcher JP, Hughes JP, Harvey IF (1994) Life expectancy and egg load affect oviposition decisions of a solitary parasitoid. Proc R Soc Lond B Biol Sci 258:163-167. doi:10. 1098/rspb.1994.0157

Giunti G, Canale A, Messing RH, Donati E, Stefanini C, Michaud JP, Benelli G (2015) Parasitoid learning: current knowledge and implications for biological control. Biol Control 90:208-219. doi:10.1016/j.biocontrol.2015.06. 007

González PI, Montoya P, Perez-Lachaud G, Cancino J, Liedo P (2007) Superparasitism in mass reared Diachasmimorpha longicaudata (Ashmead) (Hymenoptera: Braconidae), a parasitoid of fruit flies (Diptera: Tephritidae). Biol Control 40:320-326. doi:10.1016/j.biocontrol.2006.11.009

Harris EJ, Okamoto RY (1991) A method for rearing Biosteres arisanus (Hymenoptera: Braconidae) in the laboratory. J Econ Entomol 84:417-422. doi:10.1093/jee/84.2.417

Harris EJ, Bautista RC, Vargas RI, Jang EB, Eitam A, Leblanc L (2010) Suppression of melon fly (Diptera: Tephritidae) populations with releases of Fopius arisanus and Psyttalia fletcheri (Hymenoptera: Braconidae) in North Shore Oahu, HI, USA. BioControl 55:593-599. doi:10.1007/s10526010-9282-1

Manoukis N, Geib S, Seo D, Mckenney M, Vargas R, Jang E (2011) An optimized protocol for rearing Fopius arisanus, a parasitoid of Tephritid fruit flies. J Vis Exp JoVE. doi:10. 3791/2901

Minkenberg OPJM, Tatar M, Rosenheim JA (1992) Egg load as a major source of variability in insect foraging and oviposition behavior. Oikos 65:134-142. doi:10.2307/ 3544896

Mohamed SA, Ekesi S, Hanna R (2010) Old and new hostparasitoid associations: parasitism of the invasive fruit fly Bactrocera invadens (Diptera: Tephritidae) and five African fruit fly species by Fopius arisanus, an Asian opiine parasitoid. Biocontrol Sci Technol 20:183-196. doi:10. 1080/09583150903447794

Montoya P, Liedo P, Benrey B, Barrera JF, Cancino J, Aluja M (2000) Functional response and superparasitism by $\mathrm{Di}$ achasmimorpha longicaudata (Hymenoptera: Braconidae), a parasitoid of fruit flies (Diptera: Tephritidae). Ann Entomol Soc Am 93:47-54. doi:10.1603/00138746(2000)093[0047:FRASBD]2.0.CO;2

Montoya P, Pérez-Lachaud G, Liedo P (2012) Superparasitism in the fruit fly parasitoid Diachasmimorpha longicaudata (Hymenoptera: Braconidae) and the implications for mass rearing and augmentative release. Insects 3:900-911. doi:10.3390/insects3040900

Purcell MF (1998) Contribution of biological control to integrated pest management of Tephritid fruit flies in the tropics and subtropics. Integr Pest Manag Rev 3:63-83. doi:10.1023/A:1009647429498

Ramadan MM, Wong TTY, Beardsley JW (1992) Reproductive behavior of Biosteres arisanus (Sonan) (Hymenoptera: Braconidae), an egg-larval parasitoid of the oriental fruit fly. Biol Control 2:28-34. doi:10.1016/1049-9644(92)90072-L

Ramadan MM, Wong TTY, Mcinnis DO (1994) Reproductive biology of Biosteres arisanus (Sonan), an egg larval parasitoid of the oriental fruit fly. Biol Control 4:93-100. doi:10.1006/bcon.1994.1016

Rousse P, Harris ED, Quilici S (2005) Fopius arisanus, an eggpupal parasitoid of Tephritidae. Overview. Biocontrol News Inf 26:59N-69N

Rousse P, Chiroleu F, Domerg C, Quilici S (2007) Naive Fopius arisanus females respond mainly to achromatic cues. Biol Control 43:41-48. doi:10.1016/j.biocontrol.2007.06.009

Segura DF, Viscarret MM, Carabajal Paladino LZ, Ovruski SM, Cladera JL (2007) Role of visual information and learning in habitat selection by a generalist parasitoid foraging for concealed hosts. Anim Behav 74:131-142. doi:10.1016/j. anbehav.2006.12.005

Snowball GJ, Wilson F, Lukins RG (1962) Culture and consignment techiques used for parasites introduced against Queensland fruit fly (Strumeta tryoni (Frogg.)). Aust J Agric Res 13:233-248. doi:10.1071/AR9620233

Spencer JP, Fujita BH (1997) A procedural manual for mass rearing four species of tephritid fruit flies. USDA-ARS, Honolulu

Tanaka N, Steiner LF, Ohinata K, Okamoto R (1969) Low-cost larval rearing medium for mass production of oriental and mediterranean fruit flies. J Econ Entomol 62:967-968. doi:10.1093/jee/62.4.967

van Alphen JJ, Visser ME (1990) Superparasitism as an adaptive strategy for insect parasitoids. Annu Rev Entomol 35:59-79. doi:10.1146/annurev.en.35.010190.000423

Vargas RI (1989) Mass production of tephritid fruit flies. In: Robinson AS, Hooper G (eds) World crop pests fruit flies: their biology, natural enemies and control. Academic Press, New York, pp 141-151

Vargas RI, Stark JD, Uchida GK, Purcell M (1993) Opiine parasitoids (Hymenoptera: Braconidae) of Oriental fruit fly (Diptera: Tephritidae) on Kauai Island, Hawaii: Islandwide relative abundance and parasitism rates in wild and orchard guava habitats. Environ Entomol 22:246-253. doi:10. 1093/ee/22.1.246

Vargas RI, Leblanc L, Putoa R, Eitam A (2007) Impact of introduction of Bactrocera dorsalis (Diptera: Tephritidae) and classical biological control releases of Fopius arisanus (Hymenoptera: Braconidae) on economically important fruit flies in French Polynesia. J Econ Entomol 100:670-679

Vargas RI, Leblanc L, Harris EJ, Manoukis NC (2012a) Regional suppression of Bactrocera fruit flies (Diptera: Tephritidae) in the Pacific through biological control and prospects for future introductions into other areas of the world. Insects 3:727-742. doi:10.3390/insects3030727

Vargas RI, Leblanc L, Putoa R, Piñero JC (2012b) Population dynamics of three Bactrocera spp. fruit flies (Diptera: Tephritidae) and two introduced natural enemies, Fopius arisanus (Sonan) and Diachasmimorpha longicaudata (Ashmead) (Hymenoptera: Braconidae), after an invasion by Bactrocera dorsalis (Hendel) in Tahiti. Biol Control 60:199-206. doi:10.1016/j.biocontrol.2011.10.012

Wang X-G, Messing RH (2003) Egg maturation in the parasitoid Fopius arisanus (Hymenoptera: Braconidae): do host-associated stimuli promote ovarian development? Ann Entomol Soc Am 96:571-578. doi:10.1603/00138746(2003)096[0571:EMITPF]2.0.CO;2

Wang X-G, Messing RH (2008) Role of egg-laying experience in avoidance of superparasitism by fruit fly parasitoid 
Fopius arisanus (Hymenoptera: Braconidae). Ann Entomol Soc Am 101:656-663. doi:10.1603/0013-8746(2008) 101[656:ROEEIA]2.0.CO;2

Yamada YY, Miyamoto K (1998) Payoff from self and conspecific superparasitism in a Dryinid parasitoid, Haplogonatopus atratus. Oikos 81:209-216. doi:10.2307/3547042

Rafael da Silva Gonçalves has been working especially with integrated pest management, biological control, bioecology of pests and natural enemies, and mass rearing techniques. Currently Dr. Gonçalves is developing projects related to the integrated management of fruit flies, focused in the use of native species of parasitoids.

Nicholas C. Manoukis' research is focused on tephritid ecology, behavior and biological control through a combination of field experiments and computer models. Most of his current work is on C. capitata, B. dorsalis and B. cucurbitae, three of the four species of economic importance in Hawaii and of quarantine concern for the US Mainland. Dr. Manoukis is the scientific lead on an Area-Wide program on Coffee Berry Borer, a new invasive pest in Hawaii. He has been involved in projects to mediate the international transfer of fruit fly parasitoids. Previously he spent nearly a decade studying the ecology and behavior of A. gambiae, a major malaria vector, in Mali West Africa.

Dr. Dori Edson Nava is a researcher in entomology at Empresa Brasileira de Pesquisa Agropecuária (EMBRAPA). He works in one of its branches in the south of Brazil"Embrapa Clima Temperado"-in the state of Rio Grande do Sul, in the city of Pelotas. He is also a teacher at the Universidade Federal de Pelotas (UFPel) in one of its post graduation programs, Health Plant Requirements Program. He took his post graduation (master's degree and doctor's degree) at the Universidade de São Paulo (USP) in the city of Piracicaba, tutored by the professor José Roberto Postali Parra. In 2016 he held his post-doctorate (visiting researcher) in the Ecology, Evolution and Agriculture Laboratory at the Department of Entomology and Nematology of the University of California, Davis, under supervision of Dr. Jay Rosenheim. Dr. Nava's research is focused on bioecology and biological control of insects pest in fruit trees (peaches, apples and also citrus). 